УДК 631.459.01:630*116.64

ОЦЕНКА УСТОЙЧИВОСТИ ЭРОЗИОННЫХ СКЛОНОВ ПО ПОКАЗАТЕЛЯМ ДИГРЕССИИ И СТЕПЕНИ ИХ ЗАРАСТАНИЯ

\author{
Маштаков Д.А., Автономов А.Н. \\ ФГБОУ ВО «Саратовский государственный аграрный университет им. Н.И. Вавилова», \\ Capamoв, e-mail: lmsus1920@mail.ru
}

\begin{abstract}
Агроэкологические системы склонов испытывают состояние стресса по причине постоянных динамических подвижек, особенно на склонах большой крутизны. Нами сформулировано представление о критических уровнях в процессе динамики склоновых агроэкологических систем, которое в последующем рассмотрено как показатель устойчивости. Анализируя динамические процессы на склонах, в качестве критических авторы выделили стадии дигрессии склоновой поверхности под воздействием эрозионных процессов. Объектом исследования являются эрозионные склоны оврагов и балок в условиях лесостепи Приволжской возвышенности. Цель исследования: разработать параметры оценки устойчивости эрозионных склонов по результатам исследований и анализа литературных источников. Предлагается относить к динамике изменений не только изменения видового состава, но и изменения степени деградации по показателям зарастания склоновых участков, позволяющие установить процессы вторичной сукцессии по мере разрушения склоновой поверхности. Согласно нашей концепции изменения видового разнообразия, на эрозионных склонах могут сопровождаться за счет появления чужеродных растений вследствие утраты устойчивости и потери биологического разнообразия и охранных функций защитных лесных насаждений. При этом число видов может увеличиваться, но эрозионный склон постепенно теряет свою устойчивость. Количественная оценка степени зарастания по показателям подроста и качественная их характеристика дают представление о соответствии лесорастительных условий склона экологическим требованиям самосева древесных пород. Установлено, что число самосева на склонах с повышением стадии дигрессии закономерно снижается. Численность самосева, по сравнению со всходами, в 2-4 раза меньше независимо от степени дигрессии склона. На контроле и на участке I стадии дигрессии число всходов, самосева явно отличаются, что сказывается на показателе встречаемости. На остальных участках встречаемость составляет 53-100\%, что подтверждает неравномерность зарастания склона по площади.
\end{abstract}

Ключевые слова: оценка, склон, устойчивость, дигрессия, степень зарастания земель, подрост, самосев

\title{
ASSESSMENT OF THE EROSION STABILITY OF SLOPES IN THE TERMS OF DIGRESSION AND THE DEGREE OF THEIR OVERGROWTH
}

\author{
Mashtakov D.A., Avtonomov A.N. \\ Saratov State Vavilov Agrarian University, Saratov, e-mail: Imsus1920@mail.ru
}

\begin{abstract}
Agroecological systems of slopes experience stress due to constant dynamic movements, especially on the slopes of high steepness. We have formulated the idea of critical levels in the process of the dynamics of slope agroecological systems, which is subsequently considered as an indicator of sustainability. When analyzing the dynamic processes on the slopes, we identified the digression of the slope surface under the influence of erosion processes as a critical stage. The object of research is the erosion slopes of ravines and gullies in the forest-steppe conditions of the Volga upland. The purpose of the study is to develop parameters for assessing the stability of erosion slopes based on the results of research and analysis of literature sources. Results and discussion. It is proposed to refer to the dynamics of changes not only in species composition, but also changes in the degree of degradation in terms of overgrowth of slope areas, allowing to establish the processes of secondary succession as the destruction of the slope surface. According to our concept of the changes of species diversity, erosion on slopes may be accompanied by the appearance of alien plants in consequence of the stability, biological diversity and protective functions of the protective forest plantations loss. The number of species may increase, but the erosion slope gradually loses its stability. Quantitative assessment of the degree of overgrowth in terms of undergrowth and their qualitative characteristics give an idea of compliance of the slope forest conditions with the environmental requirements of self-seeding tree species. It was found that the number of self-seeding on the slopes with increasing stage of digression naturally decreases. The number of self-seeding, compared with seedlings, 2-4 times less, regardless of the degree of digression of the slope. On the control and on the site of stage I of digression, the number of shoots of self-seeding clearly differ, which affects the incidence rate. In other areas, the occurrence is $53-100 \%$, which confirms the uneven of overgrowing of the slope area
\end{abstract}

Keywords: assessment, slope, stability, digression, degree of land overgrowth, undergrowth, self-seeding

Проблемы устойчивости склоновых земель к воздействию эрозии являются основополагающими в современной агролесомелиорации, однако до сих пор само определение устойчивости остается неоднозначным. Устойчивое функционирование агроэкологических систем неразрывно свя- зывается с понятием критического состояния. Само понятие критического состояния также трактуется по-разному. Л.А. Жукова, T.А. Полянская [1] под критическим понимают необратимое в существующих условиях изменение, приводящее к нарушению организации данной системы. В.И. Дани- 
лов-Данильян [2] указывает, что в критическом состоянии происходит перестройка экосистемы с заменой некоторых или всех элементов, после чего может следовать ее полное распадение или, наоборот, формирование нового гомеостатического уровня. В условиях отсутствия динамических подвижек биотопа критическое состояние может быть связано аномалиями климатических условий (засуха, наводнение и т.д.) или стихийными бедствиями, к примеру пожарами.

Агроэкологические системы склонов испытывают состояние стресса по причине постоянных динамических подвижек, особенно на склонах большой крутизны [3]. Вниз по склонам происходит перемещение рыхлых масс обломочного материала, при этом характер перемещения определяется крутизной склона, составом слагающих его пород и воздействующими на склон факторами. Особенно резко это проявляется при усилении поверхностного стока. Нами сформулировано представление о критических уровнях в процессе динамики склоновых агроэкологических систем, которое в последующем рассмотрено как показатель устойчивости. Анализируя динамические процессы на склонах, некоторые авторы в качестве критической выделяют уже вторую стадию дигрессии, другие же, наоборот, и на последней не усматривают критического уровня расстройства процессов авторегуляции (самовозобновления эдификатора). Широкая дискуссия развернулась и по вопросу о роли динамики видового состава в процессе дестабилизации природных экосистем. При этом сложилось убежденное мнение, что потеря определенной части видового разнообразия (до 10-20\% от состава исходного ценоза) приводит к уничтожению конкретной экосистемы. Однако А.А. Титлянова [4] считает, что именно видовая структура обладает наименьшей сопротивляемостью и первой реагирует на возмущение, когда еще вся экосистема достаточно постоянна по видовому составу и не теряет устойчивости. Л.А. Жукова, Т.А. Полянская [5] в связи с этим отмечают, что сохраниться в стрессовых экологических ситуациях могут только в высшей степени динамичные и устойчивые экосистемы.

Цель исследования: провести оценку устойчивости склонов по показателям их зарастания в зависимости от степени дигрессии под воздействием эрозии.

\section{Материалы и методы исследования}

Объектом исследования являются эрозионные склоны оврагов и балок в условиях лесостепи Приволжской возвышенности на эрозионных склонах Ильинского участкового лесничество Чувашская Республика Приволжский подрайон, Руткинского лесхоза Республики Марий Эл - Приволжский подрайон и Новочеремшанского лесничества Цильнинского района Ульяновской области - Кубня - Булинский подрайон. На территории Ильинского лесничества объектами исследования явились теневые и световые склоны, выведенные из сельскохозяйственного оборота. Склоны лишены древесной растительности, травяной покров представлен разнотравьем и характеризуются разной степенью дигрессии. Склон теневой экспозиции протяженностью - 74,4 м, крутизной $-32^{\circ}$. Склон солнечной экспозиции протяженностью 160 м, крутизной $34^{\circ}$. На территории Руткинского лесхоза Республики Марий Эл склоны представлены сельскохозяйственными неиспользуемыми заросшими землями. Крутизна склона солнечной экспозиции $-29^{\circ}$, длина - 184 м, крутизна теневого склона $43^{\circ}$, протяженность - 74 м. Склон в нижней части покрыт сплошной плотной дерниной. В Новочеремшанском лесничестве Цильнинского района Ульяновской области склон солнечной экспозиции протяженностью 38 м имеет крутизну $17^{\circ}$, участок водораздельного плато - до $30^{\circ}$ характеризуется разной степенью дигрессии. В присклоновой зоне созданы искусственные противоэрозионные насаждения сосны обыкновенной на площади 1,2 га, возраст 9 лет.

Исследования проводили в период с 2014 по 2017 г. Пробные площади закладывались в соответствии с отраслевым стандартом (ОСТ 56-69-83) - «Площади пробные лесоустроительные: методы закладки» и методики [6]. Для оценки стадии дегрессии был использован трансектный метод, который основан на определении отношения нарушенной площади напочвенного покрова к общей площади обследуемого склона. При этом на ходовых линиях, равномерно охватывающих обследуемую территорию, замеряли протяженность нарушенной эрозией длины, и соотносили ее к общей длине ходовых линий. Протяженность их при погрешности $0,1 \%$, составляла 500 м на каждый гектар обследуемой площади. По данным измерений и соответствующих подсчетов, выделяли четыре стадии дигрессии и контроль: к первой стадии 
относили участки, на которых нарушенная плоскостной эрозией площадь составляет $15-30 \%$; ко второй - 31-45\%; к третьей 46-60\%; к четвертой - более $60 \%$; контролем служили залуженные или занятые защитными насаждениями без признаков повреждения участки склонов. Кроме того, для оценки устойчивости использовали показатель естественного зарастания склонов на пробных площадях размером 1х1 м, в количестве не менее 25 шт. на каждом склоне по методике А.В. Побединского [7] по числу самосева, всходов и подроста. Численное значение самосева определяли по количеству осыпавшихся семян на пробных площадях в феврале, марте. Численное значение всходов определяли в мае, а число подроста учитывали по общему их количеству, высотой от 0,5 до 1,5 м. Пробные площадки закладывали таким образом, чтобы охватить всю исследуемую площадь склона от бровки до долины оврага. Также оценивали равномерность распределения всходов и подроста на склоновой поверхности. Равномерность распределения оценивали по показателю встречаемости, путем деления числа учетных площадок, занятых всходами и подростом к общему числу площадок на единице площади. Жизненное состояние подроста оценивали путем выделения 4 категорий состояния растений: здоровые, ослабленные, усыхающие и усохшие [8]. Результаты исследований обрабатывались методами математической статистки [7]. Расчет жизненного состояния проводили по формуле:

$$
L=\frac{100 n_{1}+70 n_{2}+10 n_{3}}{N},
$$

где $L$ - относительное жизненное состояние подроста; $n_{1}, n_{2}, n_{3}$ - число здоровых, ослабленных, усыхающих и усохших деревьев на 1 га соответственно; $N$ - общее число подроста, включая сухие, на 1 га. При показателе $L=100-80 \%$ участок склона оценивали, как устойчивый, при 79-50\% устойчивость ослаблена, при 49-20\% устойчивость сильно ослаблена и ниже $20 \%$ - неустойчивый склон.

\section{Результаты исследования и их обсуждение}

Оценивать устойчивость защитных лесных насаждений на склоновых землях только по показателям изменений состава и структуры растений крайне недостаточно. Необходимо расширить классическое понимание изменений, не ограничиваясь лишь изучением видового состава древесно-кустарниковой и травянистой растительности с динамикой степени представленности отдельных видов. В данной работе предлагается использовать данные по зарастанию склонов в зависимости от степени их дигрессии под воздействием эрозии как показатель устойчивости склона. В зависимости от степени дигрессии склоновых участков под воздействием эрозии меняется видовой и количественный состав растительности. Под дигрессией в данной работе понимается ухудшение состояния экосистем склонов под воздействием водной эрозии. Согласно нашей концепции естественное зарастание склона древесной растительностью находится в зависимости от типов условий местопроизрастания (ТУМ). Условия роста и развития растений на склоне зависит от степени дигрессии плодородного слоя почвы на склоне. На стадии самосева, всходов и подроста требования растений к условиям среды постоянно меняются. Приведенные на рис. 1 данные показывают снижение количества всходов и подроста на склонах в зависимости от стадии дигрессии, что объясняется неоднородностью типов условий местопроизрастания в результате плоскостной эрозии, нарушением целостности живого напочвенного покрова и ухудшением почвенно-экологических условий для роста растений $[9,10]$. Зарастание склона в Новочеремшанском лесничестве Цильнинского района Ульяновской области на солнечной экспозиции отличается не только снижением обилия и встречаемости, но и сменой доминирующих видов древесных растений. В составе самосева встречаются семена сосны обыкновенной, березы повислой, клена американского, липы мелколистной, вяза гладкого, ели европейской, клена остролистного, ольхи серой. На стадии всходов численность древесных растений сокращается почти в два раза, по стадиям дигрессии, всходы липы мелколистной, вяза гладкого, клена остролистного, ели европейской не могут развиваться из-за высокой температуры и недостатка влаги в почве. Доминирующими видами на стадии подроста на световых склонах являются клен американский, береза повислая, а в низовых ТУМ встречаются самосев сосны обыкновенной.

Количество всходов на пробных участках, по сравнению с числом семян в 2-4 раза меньше в зависимости от степени дигрессии склона. На участках II-IV степени дигрессии самосев древесных растений 93-100\%, 
встречаемость всходов - от 53 до $100 \%$, а встречаемость подроста от 10 до $48 \%$. Аналогичные данные получены по показателям встречаемости и обилия. Сопоставление встречаемости видов по экспозициям склонов показало неоднородность соотношений фактического их количества по подрайонам. На световых склонах (южной и западной экспозиций) количество здорового подроста почти в 2 раза меньше по сравнению с теневыми (северной и восточной экспозиций). Данная закономерность сохраняется по всем изученным почвенно-экологическим подрайонам лесостепи Приволжской возвышенности. На примере опытных участков в Ильинском лесничестве Минприроды Чувашской Республики наглядно видна зависимость по- казателя встречаемости самосева, всходов и подроста от степени дигрессии склона (рис. 2).

Жизненное состояние подроста определяет успешность формирования насаждения на склонах. В зависимости от экспозиции склона показатели жизненного состояния меняются. Количественная оценка степени зарастания по показателям подроста и качественной их характеристики дают представление о соответствии лесорастительных условий склона экологическим требованиям древесных пород. Представленные в исследовании участки кроме восточного и западного склонов в Ильинском участковом лесничестве Чувашской Республики относятся к ослабленным склонам по устойчивости (рис. 3-5).

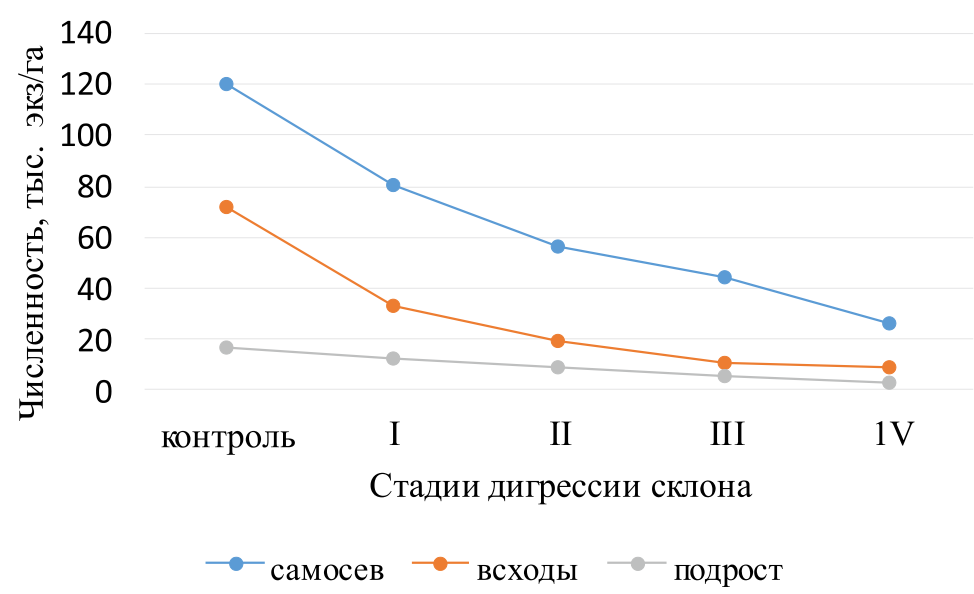

Рис. 1. Изменения числа растений на стадии самосева, всходов и подроста при зарастании склона в зависимости от степени дигрессии

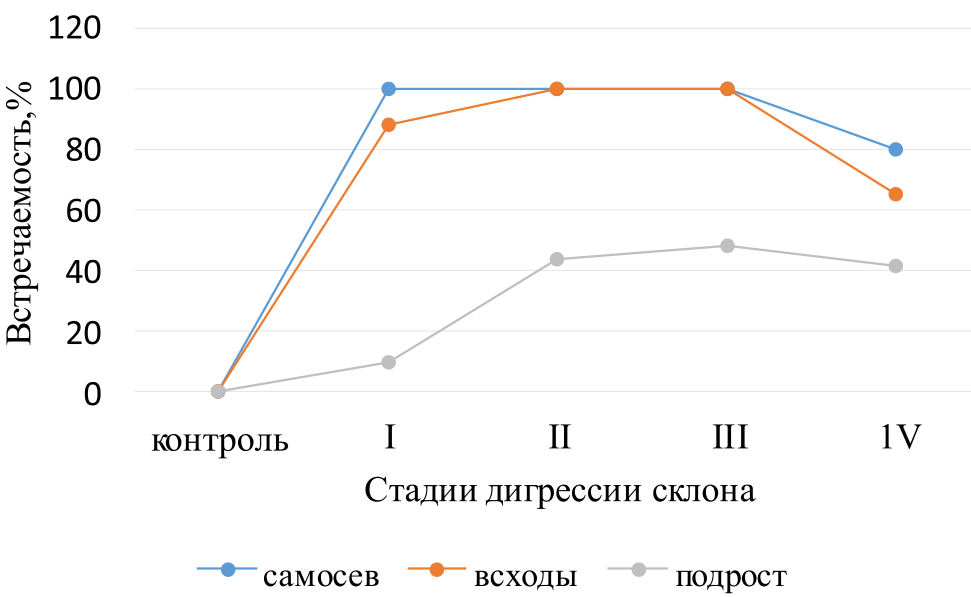

Рис. 2. Изменения показателей встречаемости при зарастании склона в зависимости от степени дигрессии (Ильинское лесничество Минприроды Чувашской Республики) 


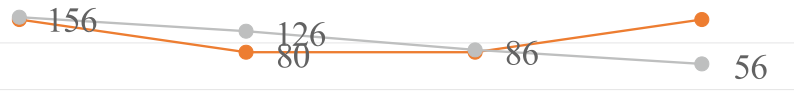

\begin{tabular}{|c|c|c|}
\hline Южный склон & $\begin{array}{c}\text { Северный } \\
\text { склон }\end{array}$ & $\begin{array}{c}\text { Восточный } \\
\text { склон }\end{array}$ \\
\hline
\end{tabular}

Экспозиция склона

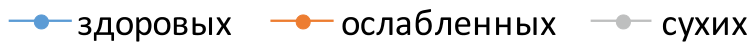

Рис. 3. Жизненное состояние подроста по экспозищиям склона в Приволюском подрайоне (Ильинское лесничество Минприроды Чувашской Республики)

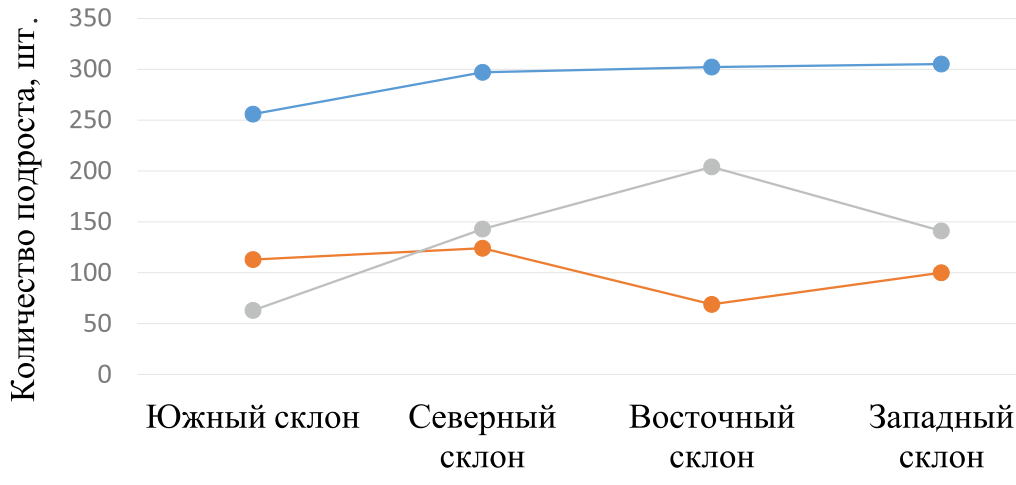

Экспозиция склона

$\longrightarrow$-здоровых $\multimap$ ослабленных $\multimap-$ сухих

Рис. 4. Жизненное состояние подроста по экспозициям склона в Кубня-Булинском подрайоне (Ульяновская область)

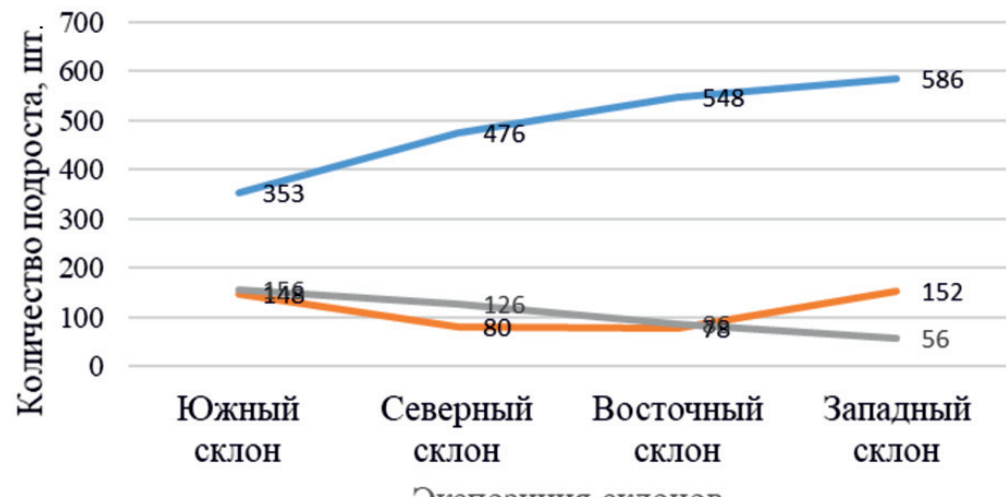

-здоровых -ослабленных - сухих

Рис. 5. Жизненное состояние подроста по экспозициям склона в Приволжском подрайоне (Республика Марий Эл) 
Количество сухого и ослабленного подроста на южных склонах значительно выше по сравнению с западными и восточными склонами. Необходимо отметить, что количество ослабленных и сухих деревьев в сумме составляет 70,4\% от общего количества подроста на склонах южной экспозиции в Кубня-Булинском подрайоне (Ульяновской области), в то время как этот показатель для южных районов Республики Марий Эл и северных районов Чувашской Республики составляет 26,8\% (Приволжском подрайоне).

\section{Выводы}

Проведенные исследования позволяют сделать следующие выводы:

1. Выделены четыре стадии дигрессии склоновых участков: к первой стадии относятся участки, на которых нарушенная плоскостной эрозией площадь составляет 15-30\%; ко второй - 31-45\%; к третьей 46-60\%; к четвертой - более $60 \%$.

2. При высоких показателях числа самосева, количество растений на стадии всходов и подроста на склонах меняется в зависимости от стадии дигрессии склоновой поверхности.

3. В зависимости от экспозиции склона и лесорастительного подрайона в лесостепи Приволжской возвышенности меняется соотношение здоровых, ослабленных и сухих растений. На световых склонах (южной и западной экспозиции) число сухого и ослабленного подроста достигает до $70 \%$, а на теневых склонах (северной и восточной экспозиции) в пределах 21-29\%, что может выступать показателем устойчивости склонов.

\section{Список литературы / References}

1. Жукова Л.А., Полянская Т.А. Экологическое разнообразие бореальной лесной и бореальной опушечной эколого-ценотической группы лесных растений // Вестник Казанского государственного аграрного университета. 2010. Т. 5. № 1. C. $140-146$.

Zhukova L.A., Polyanskaya T.A. Ecological diversity of forest and forest plants, forest and forest plants, forest group, boreal and boreal variety // Vestnik of the Kazan state agrarian University. 2010. Vol. 5. № 1. P. 140-145 (in Russian).

2. Данилов-Данильян В.И. Об устойчивости экосистем // Экосистемы: экология и динамика. 2018. Т. 2. № 1. C. 5-12.
Danilov-Danilyan V.I. On ecosystem stability // Ecosystems: ecology and dynamics. 2018. V. 2. № 1. P. 5-12 (in Russian).

3. Маштаков Д.А., Автономов А.Н., Проездов П.Н. Концепция создания противоэрозионных защитных лесных насаждений в лесостепи Приволжской возвышенности // Успехи современного естествознания. 2018. № 6. С. 37-42.

Mashtakov D.A., Avtonomov A.N., Proesdov P.N. The Concept on Creation of Protective Anti-Erosion Forest Plants in the Forest-Steppe of the Volga River Upland // Advances in current natural sciences. 2018. № 6. P. 37-42 (in Russian)

4. Титлянова А.А. Устойчивость травяных экосистем // Сибирский экологический журнал. 2009. № 2. С. 237-243.

Titlyanova A.A. Stability of grassland ecosystems// Contemporary Problems of Ecology. 2009. № 2. P. 119-123. DOI: $10.1134 / \mathrm{S} 1995425509020052$

5. Жукова Л.А., Полянская Т.А. О некоторых подходах к прогнозированию перспектив развития ценопопуляций растений // Вестник ТвГУ. Серия: Биология и экология. 2013. № 32. C. 160-171.

Zhukova L.A., Polyanskaya T.A. About Some Approaches to Forecasting Prospects of Development Coenopopulation of Plants // Herald of Tver State University. Series: Biology and Ecology. 2013. Vol. 32. № 31. P. 160-171 (in Russian).

6. ОСТ 56-69-83. Площади пробные лесоустроительные: методы закладки. М., 1983. 11 с.

7. Побединский А.В. Изучение лесовосстановительных процессов. М.: Наука, 1966. 64 с.

Pobedinskij A.V. the Study of reforestation processes. M.: Nauka, 1966. 64 p. (in Russian).

8. Пак Л.Н., Бобринев В.П. Диагностика жизненного состояния подроста Сосны Крылова на гарях в Цасучейском бору // Успехи современного естествознания. 2014. № 9-1. C. $102-106$

Pak L.N., Bobrinev V.P. Diagnostics of the vitality of the undergrowth of Pine Krylov on burned in tsasucheisky Boru // Advances in current natural sciences. 2014. № 9-1. P. 102-106 (in Russian).

9. Немченко В.А. Влияние крутизны и экспозиции склона на структуру и динамику лесостепных нагорных дубрав участка «Лес на Ворскле» заповедника «Белогорье» // Материалы Международной научно-практической конференции, посвяшенной 130-летию со дня рождения В.В. Алехина г. Курск, пос. Заповедный (15-18 января 2012). Курск, 2012. C. $126-131$

Nemchenko V.A. The influence of the steepness and the exposure of the slope on the structure and dynamics of foreststeppe upland oak forests of the «Forest on Vorskla» reserve «Belogorie»// Proceedings of the international scientific and practical conference dedicated to the 130-th anniversary of the birth of V. Alekhine Kursk-reserved village (15-18 January, 2012). Kursk, 2012. P. 126-131 (in Russian).

11. Автономов А.Н. Диагностика устойчивости травянистой растительности на землях склонов экзогенного происхождения // Современные проблемы науки и образования. 2013. № 6. [Электронный ресурс]. URL: http://scienceeducation.ru/ru/article/view?id=11536 (дата обращения: 16.02.2019).

10. Avtonomov A.N. Diagnostics of herbaceous vegetation on the lands of exogenous origin slopes. // Modern problems of science and education. 2013. № 6. [Electronic resource]. URL: http://science-education.ru/ru/article/view?id=11536 (date of access: 16.02.2019) (in Russian). 